\title{
Development of the Happiness Index in a country
}

\author{
Sanz, Maria T. ${ }^{\text {; }}$; Caselles, Antonio ${ }^{\text {; }}$ Micó, Joan C. ${ }^{\text {c }}$ \& Soler, David ${ }^{d}$ \\ ${ }^{a}$ Departamento Didáctica de la Matemática, Universidad de Valencia, Spain, m.teresa.sanz@uv.es \\ b Departamento de Matemática Aplicada, Universidad de Valencia, Spain, antonio.caselles@uv.es \\ ${ }^{c}$ Departament de Matemàtica Aplicada, Universitat Politècnica de València, Spain, jmico@mat.upv.es \\ d Institut Universitari de Matemàtica Pura i Aplicada, Universitat Politècnica de València, Spain,dsoler@mat.upv.es
}

\begin{abstract}
In this paper, a Happiness Index is built through the Human Dignity Respect Index which is explained by Author (2014). The index is created using three main values: development, freedom and equality. But the equality is explained by solidarity, justice and peace. Then, the Happiness Index is developed with this five concepts. The aim of this paper is to obtain the minimum quantitative variables to explain these values as well as to obtain a generic formula, which allows measuring the happiness of a country/region. The term "generic" is introduced because this formula could be extrapolated to any country. The variables to obtain the Development Index are health (Life Expectancy at birth), income (Gross National Income per capita), education (Mean year of schooling and Expected years of schooling) and education quality (Primary school teachers trained to teach, Performance of 15-year-old students in reading, mathematics and science, Pupil-teacher ratio, primary school and Public expenditure on education). The Freedom Index is calculated through Net migration rate, International inbound tourists, Exports and imports and Research and development expenditure. In the case of Solidarity Index, the variables are At-risk-ofpoverty rate, Share of total population living in a dwelling with a leaking roof, damp walls, floors or foundation, or rot in window frames of floor and Material Deprivation rate. Prison population and Homicide rate are the variables which are used to obtain the Peace Index. Finally, the Justice Index is calculated with Police Officers, Professional Judges, Prison population and Crimes and violence. In this work the index is calculated for a selection of countries of European Union (Austria, Croatia, Cyprus, Czech, France, Iceland, Latvia, Lithuan, Portugal, Slovenia, Spain, Sweden and United Kingdom). This selection is produced because the data information is not available for all countries. The data information is obtained from EUROSTAT and the Human Development Report (UNDP, 2014). Finally, the Happiness Index has been compared with Overall Life Satisfaction Index from UNDP (2014).
\end{abstract}

Keywords: Happiness Index, UNDP, Overall Life Satisfaction Index. 


\section{Introduction}

The interest to measure the happiness is increasing in last years. Authorities, academic and professionals are committed to improve nonmonetary welfare of people.

In this paper, a Happiness Index is built with quantitative variables that are defined in the United Nations Development Report (UNDP) and EUROSTAT.

The literature review shows differents authors who try to measure the happiness of people through satisfaction enquiries. George Gallup created the GNW (Gross National Well-Being), in which the state of person is measured from 1 to 10. The scale of life satisfaction of Diener (1985), in which happiness is measured by 5 questions that are answered on a scale from 1 to 7 . The scale of subjective happiness created by Lyubomirsky (1999), where four questions measurethe happiness on a scale from 1 to 7 .

Moreover, there are other organizations that try to measure the happiness of a country, as The Happy Planet Index (HPI) is a measure which captures the degree to which long and happy lives are achieved per unit of environmental impact. It is calculated through, life expectancy at birth, Experiencec well-being ladder of life (Gallup) and ecological footprint. Or the Overall Life Satisfaction Index that is created by created by Adrian G. White and is used in the UNDP Reports. In this calculation, subjective well being questions are involved about health, wealth, and access to basic education.

The Index presented in in this work is calculated through the terms that Caselles A. proposes in his research "Trying to evaluate the human dignity in a social group" which was presented in $9^{\text {th }}$ Congress of the European Union of Systems (UES-EUS). Valencia (Spain), 2014. There, an exhaustive analysis of the literature has been done to conclude that the supreme value is Human Dignity and a Human Dignity Respect Index has been proposed.

In this work, the Happiness Index has been built from the Human Dignity Respect Index. Immediate subordinated values to human dignity are development, freedom and equality. Subordinates to equality are solidarity, justice and peace. In Figure 1 the causal diagram shows the relation between them.

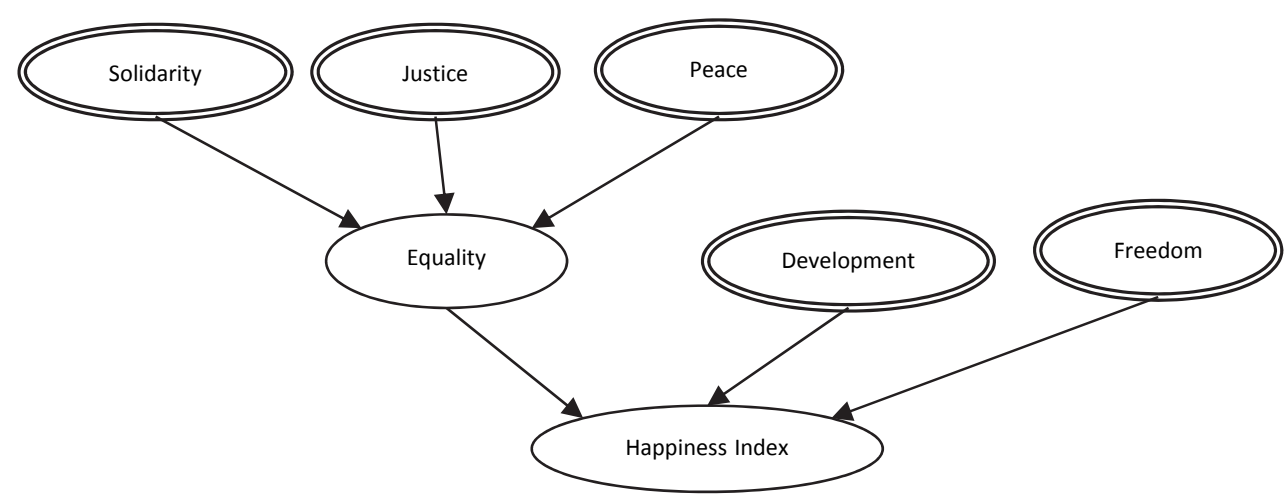

Fig 1. Causal diagram of the degree of respect to Human Dignity (which is considered equivalent to the Happiness Index).

The aim of this paper is to obtain the minimum quantitative variables to explain these values as well as to obtain a generic formula, which allows measuring the happiness of a country/region. The term "generic" is introduced because this formula could be extrapolated to any country, nevertheless in this work the 
index is calculated for a selection of countries of European Union (13 countries) in 2013, because the data information is not available for all countries in the UNDP (2014) and Eurostat.

The rest of the paper is organized as follows. Section 2 presents, explains and builts the Happiness Index through the five subindices: Solidarity, Justice, Peace, Freedom and Development. Section 3 shows the value of these subindex in the different countries. The Happiness Index and the relation with the Overall Life Satisfaction Index are developed in Section 4. Finally, some conclusions and suggestions for future research appear in Section 5.

\section{Happiness Index Formula}

The methodology to obtain the Happiness Index is the methodology used in UNDP Reports.

Minimum and maximum values (values limits) are determined to transform the real variables into variables with values between 0 and 1 . With this method, all variables can be used in the same formula because they have the same dimension.

The minimum and maximum values are obtained by two different ways. On the one hand, the variables which are obtained from UNDP Reports, in this case the maximum and minimum value are selected from a temporal serie (1996-2014) for all countries are considered in these Reports- On the other hand, the variables obtained from EUROSTAT, the maximum and minimum are chosen from a temporal serie (2000-2014) for the countries studied in this paper.

\subsection{Development}

The definition of Development from Caselles (2014) is "Options of survival and self-fulfillment. It includes: life/health, social progress (education, culture, etc.) and standard of life (economic resources, comforts, etc.).".

It is related with the Human Development Index (HDI). Nevertheless, the HDI is not used in this paper because the Happiness Index is built per gender. The Gender Development Index (GDI) is also calculated in the (UNDP). The new GDI measures gender gaps in human development achievements by accounting for disparities between women and men in three basic dimensions of human development: health, knowledge and living standards using the same component indicators and the same methodology than in the $H D I$.

Note that the GDI reveals the level of delay experienced by women respect to males and how much women advance in every dimension of human development to bridge the delay. This index provides some insight into real gender differences in human development achievements, and is useful to design regulatory tools to reduce the differences. But, the GDI is not the variables used to study the development, other variables have been used to obtain the development, and it is explained in the following paragraphs.

The quantitative variables used for this measurement are related with the $G D I$ and are explained in detail in the UNDP.

LEBI "Life expectancy at birth: Number of years a new born infant could expect to live if prevailing patterns of age-specific mortality rates at the time of birth stay the same throughout the infant's life. 


$$
\begin{gathered}
\text { lebi }=\frac{1}{\left(\frac{\text { lebf }-22.50}{87.50-22.50}\right)+\frac{\text { prpm }}{\left(\frac{l e b m-17.50}{82.50-17.50}\right)}}(1) ; \\
\text { prpf }=\frac{\text { popf }}{\text { popt }}(2) ; \quad \text { prpm }=\frac{\text { popm }}{\text { popt }} \text { (3). }
\end{gathered}
$$

Where $L E B F$ and $L E B M$ are the Female and Male Life Expectancy at Birth respectively. PRPF and $P R P M$ are the Females and Males proportion. POPF Female population, POPM Male population and $P O P T$ Total population.

MYSC Mean year of schooling: Average number of years of education received by people ages 25 and older, converted from education attainment levels using official durations of each level.

EYSC Expected years of schooling: Number of years of schooling that a child of school entrance age can expect to receive if prevailing patterns of age-specific enrolment rates persist throughout the child's life.

$E D I F$ and $E D I M$ are the Education Index by gender, which is calculated by education variables, MYSC and $E Y S C$.

$$
\begin{gathered}
\text { edif }=\frac{\frac{m y s f-0}{15-0}-\frac{e y s f-0}{18-0}}{2}(4) ; \\
e \operatorname{dim}=\frac{\frac{m y s m-0}{15-0}-\frac{\text { eysm }-0}{18-0}}{2}(5) ;
\end{gathered}
$$

Where MYSF and MYSM are the Female and Male mean year of schooling respectively and EYSF and EYSM are the Female and expected years of schooling respectively.

With Education Index by gender, is calculated the Education Index. EDIN,

$$
\text { edin }=\frac{1}{\frac{\text { prpf }}{\text { edif }}+\frac{\text { prpm }}{e \operatorname{dim}}} \text { (6); }
$$

GNIP Gross National Income per capita (PPP \$): Aggregate income of an economy generated by its production and its ownership of factors of production, less the incomes paid for the use of factors of production owned by the rest of the world, converted to international dollar." 


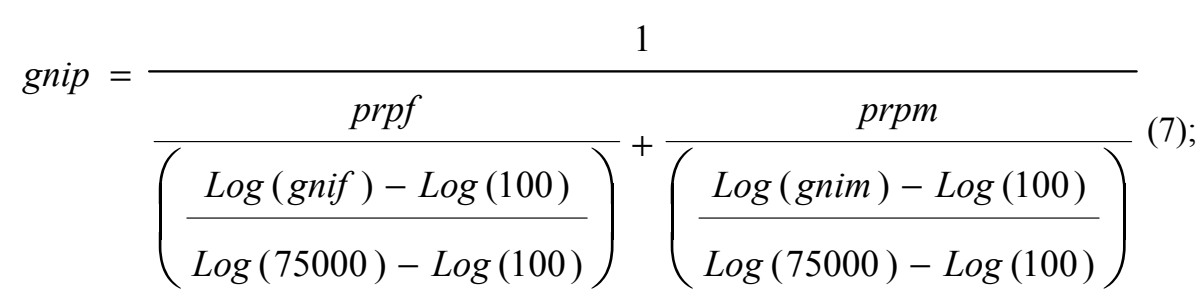

Where GNIF and GNIM are the Female and Male Gross National Income per capita respectively

Note that Health is measured with Life Expectancy at Birth. This variable can embrace the level of Health in a country.

In the case of Education the Education Quality should be included. This concept is shown in the Table 10. Education Achievments (UNDP, 2015), and the following four variables have been chosen to obtain the Education Quality, EDLI.

$$
e d l y=\sqrt[4]{\frac{p s t t-0}{100-0} \cdot p r m s \cdot\left(1-\frac{r p t s-7}{25-7}\right) \cdot \frac{\text { pexe }-2}{10-2}}(8)
$$

Where,

PSTT Primary school teachers trained to teach: Percentage of primary school teachers that have received the minimum organized teacher training (pre-service or in-service) required for teaching at the primary level.

PRMS Performance of 15-year-old students in reading (PERE), mathematics (PEMA) and science (PESC): Score obtained in testing of skills and knowledge of 15-year-old students in these subjects essential for participation in society.

$$
p r m s=\frac{\left(\frac{\text { pere }-100}{1000-100}\right)+\left(\frac{\text { pema }-100}{1000-100}\right)+\left(\frac{\text { pesc }-100}{1000-100}\right)}{3} \text { (9); }
$$

RPTS Pupil-teacher ratio, primary school: Average number of pupils per teacher in primary education in a given school year.

PEXE Public expenditure on education: Current and capital spending on education, expressed as a percentage of GDP.”.

Finally, the Development Index, DEIN, is calculated with (10),

$$
\text { dein }=\sqrt[4]{\text { lebi } \cdot \text { edin } \cdot \text { gnip } \cdot \text { edli }}(10)
$$

\subsection{Freedom}

The definition of Freedom that is given by Caselles (2014): "non-restrictions to self-fulfillment. This would be the total freedom that, obviously, in a group must be limited by the dignity of the other members of the group." The equation 11 presents the quantitive variables which have been selected to obtain the Freedom Index, FRIN, 


$$
\text { frin }=\sqrt[6]{\frac{\text { rami }-(-1000)}{1000-(-1000)} \cdot \frac{\text { inst }-0}{100-0} \cdot \frac{\text { iito }-0}{100000-0} \cdot \frac{m p s u-0}{100-0} \cdot \frac{\text { exim }-0}{100-0} \cdot \frac{\text { rede }-0}{5-0}}
$$

Where,

RAMI Net migration rate: Ratio of the difference between the number of in-migrants and out-migrants from a country to the average population, expressed per 1,000 people.

INST Stock of immigrants: Ratio of the stock of immigrants into a country, expressed as a percentage of the country's population. The definition of immigrant varies across countries but generally includes the stock of foreign born people, the stock of foreign people (according to citizenship) or a combination of the two.

IITO International inbound tourists: Arrivals of nonresident visitors (overnight visitors, tourists, sameday visitors and excursionists) at national borders.

MPSU Mobile phone subscriptions/Internet Users: Number of subscriptions for the mobile phone service expressed per 100 people.

EXIM Exports and imports: The sum of exports and imports of goods and services, expressed as a percentage of gross domestic product (GDP). It is a basic indicator of openness to foreign trade and economic integration and indicates the dependence of domestic producers on foreign demand (exports) and of domestic consumers and producers on foreign supply (imports), relative to the country's economic size (GDP).

REDE. Research and development expenditure. Current and capital expenditures (both public and private) on creative work undertaken systematically to increase knowledge and the use of knowledge for new applications, expressed as a percentage of GDP. It covers basic research, applied research and experimental development.

\subsection{Peace}

Also following Caselles (2014), peace can be defined as "absence of violence, coercion and fear".

The corresponding quantitative variables, which are extracted from the UNDP (2015), are the following:

PRPO "Prison population: Number of adult and juvenile prisoners - including pre-trial detainees, unless otherwise noted —expressed per 100,000 people.

$R A H O$ Homicide rate: Number of unlawful deaths purposefully inflicted on a person by another person, expressed per 100,000 people."

The Peace Index, PEIN, is

$$
\text { pein }=\sqrt{\left(1-\frac{\text { prpo }-0}{100000-0}\right) \cdot\left(1-\frac{\text { raho }-0}{100000-0}\right)}
$$

\subsection{Solidarity}

The definition of Solidarity that is given by Caselles (2014): "it is considered synonymous of brotherhood, that is to say, mutual aid" can include the following variables:

The information to create the Solidarity Index, SOIN, is obtained in EUROSTAT, 


$$
\operatorname{soin}=\sqrt[3]{\left(1-\frac{r i p r-0}{100-0}\right) \cdot\left(1-\frac{p l d w-0}{100-0}\right) \cdot\left(1-\frac{\text { madr }-0}{100-0}\right)}(13)
$$

$R I P R$. At-risk-of-poverty rate. The share of persons with an equivalised disposable income below the risk-of-poverty threshold, which is set at $60 \%$ of the national median equivalised disposable income (after social transfers).

$P L D W$. Share of total population living in a dwelling with a leaking roof, damp walls, floors or foundation, or rot in window frames of floor. The indicator is defined as the percentage of the total population living in a dwelling with either a leaking roof, or damp walls/floors/foundation, or rot in window frames or floor.

$M A D R$. Material Deprivation rate. The indicator is defined as the percentage of population with an enforced lack of at least three out of nine material deprivation items in the 'economic strain and durables' dimension.

\subsection{Justice}

Following Caselles (2014) justice can be considered as the set of, "mechanisms of prevention, protection and compensation for individuals or groups face to possible damages or benefits".

In this case, descriptors are not in the UNDP reports. For this reason, the information is obtained from statistical databases. In the EUROSTAT, the following information is obtained,

POOF. Police Officers. Policias por habitante.

PRJU. Professional Judges. Jueces por habitante.

PRIP. Prison population. Gente en prisión por habitante.

CRPO. Crimes and violence. \%

With these information the Justice Index, JUIN, is calculated with (14),

$$
\text { juin }=\sqrt[4]{\left(1-\frac{\frac{p o o f}{\text { popt }}-0}{1-0}\right) \cdot\left(1-\frac{\frac{\text { prju }}{\text { popt }}-0}{1-0}\right) \cdot\left(1-\frac{\frac{\text { prip }}{\text { popt }}-0}{1-0}\right) \cdot\left(1-\frac{\text { crpo }-0}{100-0}\right)}
$$

\section{The Index in the Countries}

In this section the value of each subindex is shown. The subindices is necessary to obtain the Happiness Index.

Note that attempted to perform the calculation for all countries of the European Union, but it could not be possible because of the absence of data from some of them, which is why in some tables are seen more countries than others.

Table 1 shows the Development Index, Iceland and Sweeden are the most develop countries in the EU and Bulgaria is the least develop country. 
Development of the happiness index in a country.

Table 1. Development Index by Country

\begin{tabular}{cccc}
\hline Country & Development Index & Country & Development Index \\
\hline Austria & 0.789 & Ireland & 0.803 \\
Belgium & 0.808 & Italy & 0.774 \\
Bulgaria & 0.671 & Latvia & 0.741 \\
Croatia & 0.717 & Lithuania & 0.758 \\
Cyprus & 0.775 & Poland & 0.764 \\
Czech & 0.720 & Portugal & 0.757 \\
Estonia & 0.770 & Romania & 0.677 \\
Finland & 0.803 & Slovakia & 0.721 \\
France & 0.769 & Slovenia & 0.767 \\
Germany & 0.807 & Spain & 0.775 \\
Greece & 0.750 & Sweden & 0.829 \\
Hungary & 0.742 & U.K. & 0.777 \\
Iceland & 0.837 & & \\
\hline
\end{tabular}

In regard to Freedom Index (Table 2) the most and least free countries in the EU are Denmark and Estonio respectively.

Table 2. Freedom Index by Country

\begin{tabular}{cccc}
\hline Country & Freedom Index & Country & Freedom Index \\
\hline Austria & 0.455 & Latvia & 0.288 \\
Belgium & 0.417 & Lithuania & 0.352 \\
Croatia & 0.205 & Luxembourg & 0.402 \\
Cyprus & 0.373 & Montenegro & 0.216 \\
Czech & 0.359 & Netherland & 0.422 \\
Denmark & 0.532 & Portugal & 0.180 \\
Estonia & 0.163 & Serbia & 0.312 \\
Finland & 0.363 & Slovenia & 0.243 \\
France & 0.321 & Spain & 0.364 \\
Germany & 0.380 & Sweden & 0.412 \\
Iceland & 0.326 & Switzerlan & 0.319 \\
Ireland & 0.366 & U.K. & 0.192 \\
Italy & 0.263 & & \\
\hline
\end{tabular}

The Justice and Peace Index (Table 3 and 4) are high in all countries, remark that Croatia and Iceland have the same justice index. 0.990, and the Peace Indeces are different in the third decimal. 
Table 3. Justice Index by Country

\begin{tabular}{cccc}
\hline Country & Justice Index & Country & Justice Index \\
\hline Austria & 0.961 & Malta & 0.961 \\
Bulgaria & 0.926 & Montenegro & 0.977 \\
Croatia & 0.990 & Netherland & 0.938 \\
Cyprus & 0.943 & Norway & 0.980 \\
Czech & 0.953 & Poland & 0.978 \\
Denmark & 0.965 & Portugal & 0.965 \\
Estonia & 0.959 & Romania & 0.952 \\
France & 0.945 & Serbia & 0.936 \\
Greece & 0.943 & Slovakia & 0.969 \\
Hungary & 0.956 & Slovenia & 0.971 \\
Iceland & 0.990 & Spain & 0.950 \\
Latvia & 0.963 & Sweden & 0.966 \\
Lithuania & 0.985 & U.K. & 0.944 \\
\hline
\end{tabular}

Table 4. Peace Index by Country

\begin{tabular}{lclr}
\hline Country & Peace Index & Country & Peace Index \\
\hline Austria & 0.99945 & Lithuania & 0.99891 \\
Belgium & 0.99939 & Luxembourg & 0.99970 \\
Bulgaria & 0.99734 & Montenegro & 0.99830 \\
Croatia & 0.99846 & Netherland & 0.99639 \\
Cyprus & 0.99879 & Norway & 0.99934 \\
Czech & 0.99944 & Poland & 0.99980 \\
Denmark & 0.99956 & Portugal & 0.99906 \\
Finland & 0.99967 & Romania & 0.99958 \\
France & 0.99951 & Serbia & 0.99852 \\
Germany & 0.99904 & Slovakia & 0.99927 \\
Hungary & 0.99862 & Slovenia & 0.99947 \\
Iceland & 0.99925 & Spain & 0.99923 \\
Ireland & 0.99966 & Sweden & 0.99976 \\
Italy & 0.99926 & Switzerlan & 0.99959 \\
Latvia & 0.99924 & U.K. & 0.99936 \\
\hline
\end{tabular}

Finally, the Solidarity Index (Table 5) shows the most solidarity country, Norway, and the least, Bulgaria. 
Development of the happiness index in a country.

Table 5. Solidarity Index by Country

\begin{tabular}{cccc}
\hline Country & Solidarity Index & Country & Solidarity Index \\
\hline Austria & 0.877 & Latvia & 0.703 \\
Belgium & 0.850 & Lithuania & 0.757 \\
Bulgaria & 0.661 & Luxembourg & 0.876 \\
Croatia & 0.771 & Malta & 0.843 \\
Cyprus & 0.720 & Netherland & 0.886 \\
Czech & 0.884 & Norway & 0.924 \\
Denmark & 0.875 & Poland & 0.821 \\
Estonia & 0.815 & Portugal & 0.744 \\
Finland & 0.915 & Romania & 0.710 \\
France & 0.872 & Serbia & 0.691 \\
Germany & 0.864 & Slovakia & 0.852 \\
Greece & 0.746 & Slovenia & 0.803 \\
Hungary & 0.698 & Spain & 0.820 \\
Iceland & 0.886 & Sweden & 0.910 \\
Ireland & 0.823 & Switzerlan & 0.900 \\
Italy & 0.780 & U.K. & 0.836 \\
\hline
\end{tabular}

\section{Hapiness Index vs Overall Life Satisfaction Index}

In this section the Happiness Index is calculated as

$$
\text { hain }=\sqrt[5]{\text { dein } \cdot \operatorname{frin} \cdot \text { juin } \cdot \text { pein } \cdot \operatorname{soin}}(15)
$$

Table 6 shows the Hapiness Index for each country (Formula) and the Overall Life Satisfaction Index (Satisfaction Index) which is calculated throw a quiz in UNDP. In Figure 2 the same is represented and the $r^{2}$ is 0.5027 .

Table 6. Index by Country

\begin{tabular}{ccc}
\hline COUNTRY & Formula & $\begin{array}{c}\text { Satisfaction } \\
\text { Index }\end{array}$ \\
\hline Austria & 0.74168166 & 0.74 \\
Croatia & 0.57865172 & 0.6 \\
Cyprus & 0.6654394 & 0.62 \\
Czech & 0.68312945 & 0.63 \\
France & 0.6711497 & 0.66
\end{tabular}




\begin{tabular}{ccc} 
Iceland & 0.69938758 & 0.76 \\
Latvia & 0.61657566 & 0.51 \\
Lithuan & 0.66763397 & 0.58 \\
Portuga & 0.55896431 & 0.5 \\
Sloveni & 0.61762304 & 0.61 \\
Spain & 0.68453398 & 0.63 \\
Sweden & 0.74034153 & 0.76 \\
United Kingdom & 0.58577153 & 0.69 \\
\hline
\end{tabular}

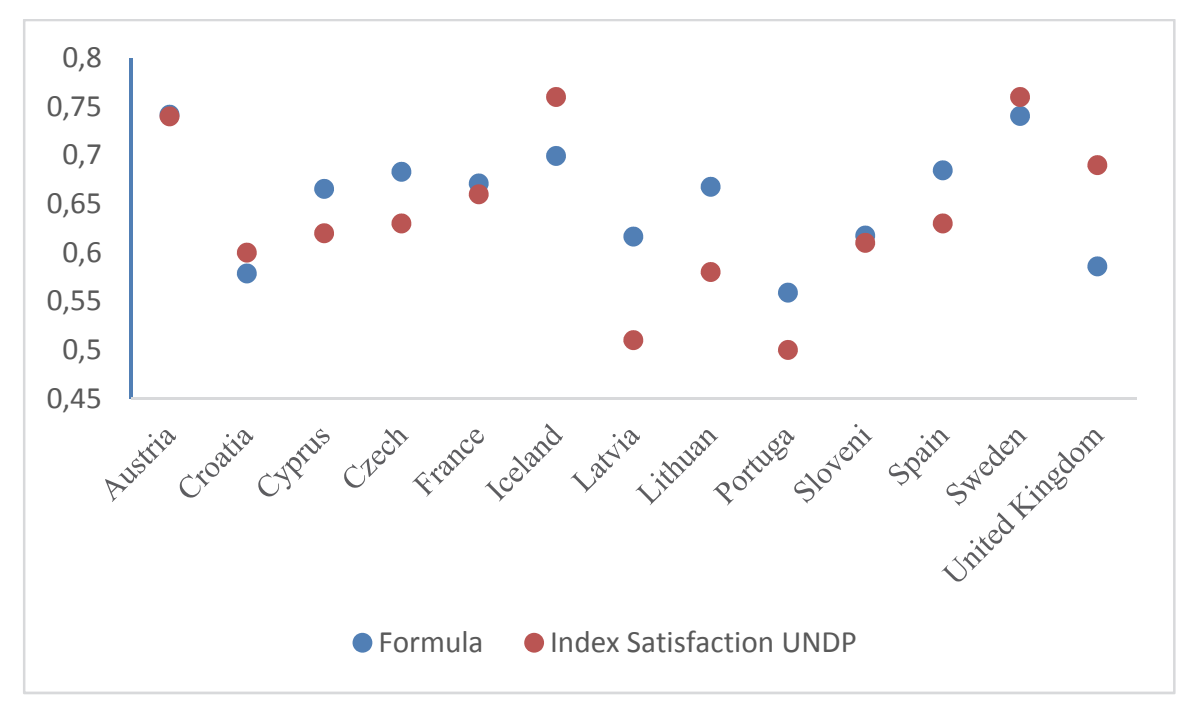

Fig 2. Happiness Index (Blue Point) and Overal Life Satisfaction Index (Red Point). $\mathrm{R}^{2}=0.502745$

\section{Conclusions}

This paper has presented the formula to calculate the Happiness Index. The qualitative variables involved are obtained from Caselles (2014) and they are the development, freedom, justice, peace and solidarity. These variables have been calculated through cuantitative variables which are defined by the UN's Human Development Report (UNDP, 2014) and also through the Eurostat.

The formula of the Hapiness Indexis is generic, i.e., it is applicable to any country in the world. That is why here the index is calculated for 13 countries of the European Union. The countries have not selected randomness, all counties studied in the UNDP (2014) have been studied in this paper but some of them have not enough data to calculate the formula completely.

This index is compared with the Overall Life Satisfaction Index presented by the UN in its reports, and notes that the value is are similar in the countries studied.

In the future work, we will try to get enough data to get calculate this index for a greater number of countries in the world, not only countries of the European Union. 
In addition, this index will be included in a socio-demographic dynamic model (Sanz et al., 2016) to observe the relation between demographic rates and the same.

\section{References}

Caselles, A. (2014) Trying to evaluate the human dignity in a social group. $9^{\text {th }}$ Congress of the European Union of Systems (UES-EUS). Valencia (Spain).

Diener, E., Emmons, R.A., Larsen, R.J. ,Griffin, S. (1985) The Satisfaction with Life Scale. Journal of Personality Assessment 49:71-5.

Lyubomirsky, S., H. Lepper. (1999) A Measure of Subjective Happiness: Preliminary Reliability and Construct Validation. Social Indicators Research 46:137-55.

Sanz, M.T, Caselles, A., Micó, J.C., Soler, D. (2015) Including an environmental quality index in a demographic model. International Journal in the Global Warming, 9(3) pp 362-396.

UNDP (2014) Human development Report 2014, Sustaining Human Progress: Reducing Vulneerabilities and Building Resilience. Published for the United Nations Developent Programme. 